\title{
POLÍTICAS SOCIAIS PARA IDOSOS: ALGUMAS REFLEXÕES A PARTIR DO ENFOQUE DE GÊNERO ${ }^{1}$
}

\author{
Josimara Delgado ${ }^{2}$ e Cristiane Silva Villa Flor ${ }^{3}$
}

\begin{abstract}
RESUMO
0 texto pretende identificar e discutir as principais tendências das políticas de proteção social ao idoso, com enfoque no gênero, relacionando-as ao modelo mais geral da atual política social brasileira. A base das discussões é a pesquisa bibliográfica e levantamentos exploratórios feitos no âmbito da pesquisa A Proteção social ao Idoso nas Políticas de Seguridade Social em Salvador.
\end{abstract}

Palavras-chave: Envelhecimento. Políticas sociais. Gerações. Gênero.

\section{SOCIAL POLICIES FOR THE ELDERLY: SOME REFLECTIONS FROM A GENDER PERSPECTIVE}

\begin{abstract}
The text aims at identifying and discussing the main tendencies of social protection of the elderly policies, focusing on gender, relating them to the most general model of social policies in Brazil today. The discussion is based on bibliographical research and exploratory data collection from The Social Protection of the Elderly in Social Security Policies in Salvador research.
\end{abstract}

Keywords: Ageing. Social policies. Generations. Gender.

\footnotetext{
${ }^{1}$ Uma versão anterior desse artigo foi proposta à organização do XV Encontro de Ciências Sociais do Norte e Nordeste e Pré-Alas Brasil, 2012.

${ }^{2}$ Doutora em Serviço Social, docente do Mestrado em Políticas Sociais e Cidadania. Universidade Católica de Salvador (UCSal), Brasil. josimaradelgado@gmail.com

3 Mestranda em Políticas Sociais e Cidadania. Universidade Católica do Salvador (UCSal)/crisvillaflor@yahoo.com.br
} 


\section{INTRODUZINDO QUESTÕES}

U

ma das possibilidades para pensarmos as novas e dinâmicas relações entre as gerações no Brasil contemporâneo é aquela aberta pela análise das políticas de proteção social voltadas aos diferentes grupos etários. Além de circunscreverem possibilidades objetivas de estabelecimento de relações de solidariedade entre mais velhos e mais jovens e de definirem direitos e deveres mútuos, as políticas de proteção social, ao criarem determinados acordos sociais, incidem também no plano das identidades sociais.

No campo específico das gerações, as políticas sociais regulam relações que estão no entremeio entre público e privado e que, historicamente, foram construídas em torno de papéis definidos de geração e de gênero.

No caso do envelhecimento, as sociedades ocidentais modernas, por meio dos sistemas de aposentadoria, consagraram um padrão de proteção e de relação intergeracional, posto na noção de que ativos financiam os inativos e de que a aposentadoria corresponderia ao período de descanso remunerado. Ao mesmo tempo em que esses sistemas promoveram garantias ao idoso trabalhador, contribuíram para a construção de estereótipos historicamente reproduzidos em torno da inatividade e dependência, atribuída aos aposentados, bem como para a desqualificação, como cidadão, do idoso que, por algum motivo, não logrou se aposentar, não possuindo renda.

As transformações ocorridas na etapa tardia do capitalismo trouxeram amplas mudanças para essa lógica sócio-cultural: a aposentadoria é questionada como direito nos discursos e práticas dos Estados nacionais em todo o mundo ocidental, sendo esse 0 eixo do desmonte das políticas sociais sob o neoliberalismo. Ao mesmo tempo, a fragilização da condição do trabalho, no interior do processo de reestruturação produtiva, deixa claro o real papel do idoso nas famílias, como provedor e transmissor de bens materiais para as gerações mais jovens. É esse mesmo processo, no entanto, que revelou a situação de muitos idosos que ainda sustentavam suas famílias, mesmo com baixos proventos, trabalhavam e, em tantos casos, sofriam violência no próprio seio doméstico.

Pretendemos discutir, nesse texto, a questão da proteção social ao idoso no contexto esboçado acima, à luz do debate sobre as gerações e gêneros. Esse é o enfoque que tem conduzido a pesquisa A Proteção social ao Idoso nas Politicas de Seguridade Social em Salvador, desenvolvida no Grupo de Pesquisa Serviço Social e Questão Social, do Mestrado em Políticas Sociais e Cidadania da Universidade Católica do Salvador, UCSal'. Os dados empíricos que servem de base para algumas das análises correspondem

\footnotetext{
${ }^{4} 0$ projeto tem como objetivo compreender quais são e como estão ocorrendo as ações de proteção social ao idoso no interior das políticas de seguridade social, saúde, previdência e assistência social na cidade de
} 
à primeira fase do trabalho que constou de uma sondagem documental e institucional sobre a proteção social ao idoso nas políticas de Seguridade. Portanto, trata-se de colocações não conclusivas, que visam tão somente provocar o debate acerca do tema, registrando sua pertinência e complexidade.

\section{A PROTEÇÃO SOCIAL AO IDOSO NO CONTEXTO DE MUDANÇAS SÓCIO-CULTURAIS}

As transformações históricas do mundo do trabalho no sentido da reestruturação produtiva modificaram profundamente o conjunto da sociedade, gerando uma complexificação das relações societárias de sua estrutura de classes e dos contratos de gênero e geração. Precarização do trabalho, desemprego, novas exigências de qualificação e escolarização redefinem o mercado de trabalho e a educação. Ao lado dessa mudança estrutural, é importante lembrar o processo caracterizado como avanço neoliberal, que marcou e marca as formas de gestão do Estado capitalista, os quais assumem uma postura privatizante, minimizando sua atuação na garantia pública dos direitos (BEHRING, 2008).

Esse processo foi responsável pelo desmonte dos sistemas de proteção social já consolidados no mundo capitalista e pela grande dificuldade de implementação de direitos conquistados, bem como pela consolidação de uma tendência à mobilização de recursos individuais e comunitários, especialmente da família, como fontes de proteção social. Além disso, um outro processo fundamental nesse contexto é a globalização, responsável pela difusão de novas tecnologias de informação, comunicação e consumo a nível mundial, gerando importantes mudanças culturais e nos padrões de consumo das populações.

Não por acaso, é nesse contexto que irrompem, de forma significativa, as problemáticas relativas às gerações. Os processos sócio-político-culturais mencionados acima, na verdade, contribuíram para que os antigos contratos públicos, de gênero e de

Salvador. 0 estudo busca identificar tendências significativas nesse universo, reunindo dados concretos sobre o funcionamento dessas políticas, seus limites, avanços e sobre, em que medida, atendem as necessidades dos idosos. Para tal, a proposta da pesquisa é fazer uma análise de instituições, legislações e políticas sociais, bem como ouvir os próprios idosos acerca de suas demandas. Além de pesquisa bibliográfica e documental sobre o tema, foi realizado um levantamento das ações de proteção ao idoso na Previdência e nas políticas de Saúde e Assistência em nível estadual e municipal. Essa investigação foi feita por meio de entrevistas com os profissionais e visitas técnicas aos serviços. Está em curso também a realização de um perfil das idosas que participam das atividades dos Centros Sociais Urbanos (CSU's), atividade que está sendo feita em parceria com a Superintendência de Assistência Social (SAS)/Coordenação de Ações Intersetoriais ( CAIS) da Secretaria de Desenvolvimento Social e Combate à Pobreza do estado da Bahia (SEDES-BA). 
geração normalmente baseados na divisão tradicional de trabalho entre homens e mulheres e na ideia de que os ativos financiam os inativos, passassem por um processo de erosão. Tais pactuações sociais começaram a não mais responder às reais necessidades de jovens e velhos, homens e mulheres em suas relações cotidianas, demandando novas formas de gestão dos acordos entre as gerações e gêneros. Nessa sociedade, volta-se a discutir, então, questões como quem tem ou não o direito de trabalhar, quem deve suprir as necessidades de quem, quem deve cuidar e receber cuidado. Um exemplo dessa situação político-social são os Estatutos da Criança e do Adolescente (BRASIL, 1990) e do Idoso (BRASIL, 2003), que buscam assegurar os direitos desses grupos sociais em um novo panorama de relações.

Desse contexto de mudanças, destaco a questão do envelhecimento. Além do já conhecido aumento do contingente de velhos da população brasileira e do aumento da longevidade da população (CAMARANO, 2003), a questão da velhice no Brasil tem se tornado cada vez mais importante, justamente em função das mudanças mencionadas acima. Na contemporaneidade, torna-se evidente o caráter complexo da questão do envelhecimento. Um dos eixos que nos permite compreender esse quadro é a crescente publicização da velhice e sua expressão como uma questão social e o surgimento de demandas específicas para o idoso em torno dos direitos e no interior das políticas.

Em termos da questão da proteção social pública ao idoso, pode-se perceber que todo esse processo de mudanças corresponde à introdução de novas concepções de políticas para essa etapa da vida. Analisando a realidade brasileira, percebemos que se pode traçar uma fronteira entre uma concepção de velhice presente nas políticas anteriores ao Estatuto do Idoso e uma outra após essa lei. Trata-se, no primeiro caso, de uma visão dos velhos como pessoas necessariamente pobres e abandonadas, sem autonomia, carentes e limitadas para a gestão de suas próprias vidas. Explica-se, assim, a associação feita, por muitos anos, e que ainda se repõe hoje, entre a velhice, a pobreza, e a doença e, pois, explica-se o caráter filantrópico e pontual dado ao trato do envelhecimento pelo Estado, semelhante ao trato dado à população pobre e incapacitada para o trabalho.

Atualmente, já após o Estatuto, percebe-se clara mudança nessa concepção, fruto inclusive de diretrizes internacionais ${ }^{5}$. Trata-se justamente da noção de velhice bemsucedida e de envelhecimento saudável que está na base da ideia de terceira idade e outros termos correlatos, como melhor idade, todos denotando uma forma de não marcar os aspectos negativos do envelhecimento e sugerindo a continuidade da vida.

\footnotetext{
${ }^{5}$ Sobre o papel dos organismos internacionais na agenda das políticas para idosos ver Camarano e Pasinato (2004) e Fonte (2002).
} 
Esse concepção, de fato, impulsionou toda uma discussão sobre direitos dos idosos e permitiu a maior visibilidade do grupo.

Contudo, é muito importante também, chamar atenção para o fato de que é esse tipo de interpretação da velhice, baseada na noção de terceira idade e no ideal do envelhecimento ativo, a qual se encontra na base de programas nascidos da iniciativa do terceiro setor e da filantropia empresarial, que tem formatado a política social para 0 idoso no Brasil contemporâneo, difundindo-se como referência universal para a gestão da velhice no país (TEIXEIRA, 2008). Esses programas contribuem para a divisão de responsabilidades no trato da questão social, nomeando a família e a comunidade como responsáveis pela proteção social ao idoso. Solange Teixeira analisa que essa é a premissa presente na criação de espaços, serviços e ações alternativos para se efetivar essa proteção, como os definidos pela Política Nacional do Idoso (PNI) e a própria Lei Orgânica da Assistência Social (LOAS): os centros de convivência, centros-dia, atendimento domiciliar e a assistência monetária por meio do Benefício de Prestação Continuada (BPC), iniciativas que reforçam como critério de inserção a vulnerabilidade e a exclusão e/ou que se pautam apenas na convivência, deixando de lado aspectos da vida material e simbólica dos idosos.

Não podemos esquecer que é uma tônica, na sociedade contemporânea, a enunciação pública dos riscos contidos no envelhecimento populacional, criando expectativas de um futuro de inseguranças e a ideia da aposentadoria como responsável pelo déficit público. Esse argumento está na base do desmantelamento da proteção social pública e do contrato público entre gerações representado pelo sistema de proteção social e expresso nos regimes de aposentadoria (KOHLI, 1995; SIMÕES, 1998). 0 que se assiste é o recuo da proteção social pública, bem como o incentivo à mobilização de recursos informais ligados à solidariedade primária, evocando um papel tradicional da família e da comunidade, sobretudo no cuidado com os segmentos mais vulneráveis como crianças e idosos.

A lógica assumida pela proteção social pública ao idoso reproduz e especifica, então, as linhas mais amplas que desenham a política social brasileira. A aposentadoria é uma importante política de proteção social para o idoso brasileiro a qual foi extremamente afetada no bojo da reestruturação produtiva e das políticas neoliberais. Ao lado da aposentadoria, a partir de 1993, o Benefício de Prestação Continuada ${ }^{6}$, previsto

\footnotetext{
${ }^{6} 0$ Benefício de Prestação Continuada (BPC), contido na Lei Orgânica da Assistência Social - LOAS (BRASIL, 1993) e na Política Nacional de Assistência Social (BRASIL, 2004), como um benefício não contributivo, é a garantia de um salário mínimo mensal às pessoas idosas, a partir de 65 anos, e às pessoas portadoras de deficiência. Ambos precisam comprovar renda familiar per capita inferior a 1/1/4 do salário mínimo para ter acesso ao benefício. Considerado juntamente com o Bolsa Família, um dos maiores programas de transferência de renda do Brasil, o BPC representa a garantia de atendimento das
} 
na Política Nacional de Assistência Social ${ }^{7}$, passa a ser um importante mecanismo de proteção à população mais velha, instaurando uma nova perspectiva nesse sentido, qual seja, a perspectiva do direito social não contributivo, uma vez que o benefício é facultado atualmente a idosos com mais de 65 anos e renda familiar per capta menor que 1/4 do salário mínimo, independente de sua contribuição previdenciária.

Contudo, o próprio crescimento dos benefícios assistenciais e sua centralidade no interior da proteção social brasileira recoloca questões como o retrocesso no campo dos direitos já consolidados na esfera da saúde e da previdência:

[...] se antes a centralidade da seguridade girava em torno da previdência, ela agora gira em torno da assistência, que assume a condição de uma política estruturadora e não como mediadora de acesso a outras políticas e a outros direitos, como é o caso do trabalho (M0TTA, 2008, p. 7).

A relação entre essas duas políticas na proteção social ao idoso revela traço importante da política social no Brasil que é a contraposição entre direitos do trabalho e direitos assistenciais. Enquanto a aposentadoria cobre os idosos que contribuíram para a Previdência, a Assistência vai se direcionar às necessidades dos idosos sem renda, pelo menos no tocante ao BPC, que não é a única ação para idosos na política de Assistência, como mostraremos mais à frente. Ao contrário, essa política elege o idoso como um de seus usuários, em função da vulnerabilidade desse grupo na sociedade brasileira, prevendo linhas específicas de ação para os mais velhos.

\section{Velhice, Gênero e Proteção Social: Considerações PRELIMINARES SOBRE SALVADOR}

necessidades básicas para a maioria de seus beneficiários. 0 Instituto Nacional de Seguridade Social INSS é o órgão executor e controlador do BPC.

${ }^{7}$ Em 2004, o Brasil aprova a Política Nacional de Assistência Social - PNAS. Essa política traduziu 0 cumprimento das deliberações da IV Conferência Nacional de Assistência Social, no sentido de buscar transformar em ações diretas os pressupostos da Constituição Federal de 1988, que instituiu a assistência social como um direito do cidadão e dever do Estado, através de definições dos princípios e das diretrizes para a sua implementação, cumprindo nova agenda para a cidadania no Brasil. O Sistema Único da Assistência Social - SUAS (BRASIL, 2005) é um sistema não contributivo, descentralizado e participativo que tem por função a gestão do conteúdo específico da assistência social no campo da proteção social brasileira, sendo este um novo reordenamento da PNAS na perspectiva de promover maior efetividade de suas ações, tendo os seus serviços, programas, projetos e benefícios reorganizados por níveis de proteção social básica e proteção social especial. Esses dois níveis estão organizados em serviços que têm como referência os Centros de Referência de Assistência Social (CRAS) para a proteção básica e os Centros de Referência Especializada de Assistência Social (CREAS) para a proteção especial. 
As mudanças contemporâneas se configuram como contexto em que 0 envelhecimento feminino vem sendo construído diferencialmente em relação a épocas anteriores. Alguns papéis rigidamente demarcados puderam ser relativizados, permitindo a vivência de experiências de lazer e sociabilidade a mulheres mais velhas. Ao mesmo tempo, as idosas assumem papéis e responsabilidades crescentes na provisão e chefia familiar, bem como no cuidado de gerações mais jovens. Do ponto de vista da emancipação feminina, esse quadro traz também ambiguidades, pois ainda que 0 aumento da visibilidade social das mulheres idosas e a ampliação de suas possibilidades de expressão pessoal sejam um dado concreto, isso não significa que a mulher idosa tenha necessariamente mais liberdade para o uso do seu tempo, pois não necessariamente está liberada de seus afazeres domésticos. Do mesmo modo, as condições objetivas das mulheres mais velhas para a vivência dessa etapa da vida, além de reproduzirem as diferenças de classe de nossa sociedade, reproduzem as desigualdades de gênero, pelo menos no tocante à questão da proteção social a essas idosas.

Nesse momento do texto, pretendemos, então, discutir a questão da proteção social aos idosos, destacando o envelhecimento feminino, a partir de uma perspectiva de gênero. Não há ainda suficientes estudos nesse sentido, pois a velhice feminina continua sendo uma realidade bastante invisível para a produção acadêmica em geral, ainda que ganhe destaque no interior da literatura sobre envelhecimento, mas, sobretudo, continua sendo invisível para as políticas sociais. Tentaremos pautar a análise na lógica de proteção social de duas políticas de Seguridade Social fundamentais na gestão do envelhecimento contemporâneo: a Previdência e a Assistência Social. 0 eixo da análise é a realidade encontrada em Salvador a partir de uma primeira aproximação ao campo.

\section{MulHeres IDOSAS: ENTRE A AssistênCIA E A PreVIdÊNCIA SOCIAL}

A noção de Seguridade Social, implantada a partir da Constituição de 1988, foi um importante fundamento para 0 redirecionamento da política social brasileira no sentido da construção de um sistema de proteção integral ao cidadão, capaz de protegêlo quando no exercício da sua vida laboral, na falta dela, na velhice e nos diferentes imprevistos que a vida lhe apresentar. No tocante à cobertura, trata-se de um sistema que integra ações contributivas, no caso da política previdenciária, e não-contributivas, como nas políticas de saúde e assistência social. A Seguridade representa, então, a introdução da Assistência no campo do direito social o que é uma inovação na cultura política brasileira (COUTO, 2006).

Antes dessa conquista, o sistema de proteção social brasileiro era exclusivamente marcado pela ótica da cidadania regulada, ou seja, de uma proteção que decorre da inserção laboral formal, tendo como financiamento originário dessa política, recursos 
advindos dos próprios trabalhadores. Esse modelo relegava, aos que ficavam de fora da formalidade do trabalho, a filantropia e uma identidade marcada por um estigma social: a incapacidade. A história da Assistência Social no Brasil, até seu ingresso na Seguridade, tem a marca da falta de financiamento e planejamento continuados e da vinculação com a população mais pobre, cujas necessidades são historicamente usadas como elemento de barganha política (VICCARI, 2008).

Contudo, a conquista da Assistência como direito se deu num momento em que 0 país redirecionava sua política social no sentido das práticas neoliberais e desse modo, a concretização da Assistência como direito vem sendo comprometida por alguns fatores: a focalização na pobreza extrema; o reforço ao assistencialismo e às formas emergenciais de atender à população; a transferência de responsabilidades do governo para a sociedade civil no trato da questão social; o reforço e ampliação dos programas de assistência em detrimento de políticas de emprego.

Essas colocações são importantes para pensarmos a questão do trato dado ao idoso e sobretudo à idosa no interior dessa política, uma vez que se trata de um dos grupos sociais que são alvo dos serviços sócio-assistenciais previstos na política, em função de sua vulnerabilidade social. Na PNAS está prevista uma significativa gama de serviços voltados para a população idosa, os quais descrevemos em seguida.

Na proteção básica temos dois tipos de serviços. 0 serviço de fortalecimento de vínculos, voltado para idosos com idade igual ou superior a 60 anos, em situação de vulnerabilidade social, que tem como foco

[...] o desenvolvimento de atividades que contribuam no processo de envelhecimento saudável, no desenvolvimento da autonomia e de sociabilidades, no fortalecimento dos vínculos familiares e do convívio comunitário e na prevenção de situações de risco social. A intervenção social deve estar pautada nas características, interesses e demandas dessa faixa etária e considerar que a vivência em grupo, as experimentações artísticas, culturais, esportivas e de lazer e a valorização das experiências vividas constituem formas privilegiadas de expressão, interação e proteção social. Devem incluir vivências que valorizam suas experiências e que estimulem e potencialize a condição de escolher e decidir (BRASIL, 2009, p. 9-10).

Esse serviço se destina especialmente: aos idosos que recebem o Benefício de Prestação Continuada; idosos de famílias beneficiárias de programas de transferência de renda; idosos com vivências de isolamento por ausência de acesso a serviços e oportunidades de convívio familiar e comunitário e cujas necessidades, interesses e disponibilidade indiquem a inclusão no serviço. Os objetivos do trabalho são: 
Contribuir para um processo de envelhecimento ativo, saudável e autônomo; assegurar espaço de encontro para os idosos e encontros intergeracionais de modo a promover a sua convivência familiar e comunitária; detectar necessidades e motivações e desenvolver potencialidades e capacidades para novos projetos de vida; propiciar vivências que valorizam as experiências e que estimulem e potencializem a condição de escolher e decidir, contribuindo para o desenvolvimento da autonomia e protagonismo social dos usuários (BRASIL, 2009, p. 12).

Ainda nesse nível de proteção, temos o Serviço de Proteção Social Básica no Domicílio para idosos e deficientes que tem como objetivo geral prevenir riscos sociais como isolamento, violência e violação de direitos.

Na Proteção Especial de média complexidade, o principal serviço é o de Proteção social especial para pessoas com deficiência, idosas e suas famílias. Esse serviço deve ofertar:

[...] atendimento especializado a famílias com pessoas com deficiência e idosos com algum grau de dependência, que tiveram suas limitações agravadas por violações de direitos, tais como: exploração da imagem, isolamento, confinamento, atitudes discriminatórias e preconceituosas no seio da família, falta de cuidados adequados por parte do cuidador, alto grau de estresse do cuidador, desvalorização da potencialidade/capacidade da pessoa, dentre outras que agravam a dependência e comprometem 0 desenvolvimento da autonomia. [...] Deve contar com equipe específica e habilitada para a prestação de serviços especializados a pessoas em situação de dependência que requeiram cuidados permanentes ou temporários. A ação da equipe será sempre pautada no reconhecimento do potencial da família e do cuidador, na aceitação e valorização da diversidade e na redução da sobrecarga do cuidador, decorrente da prestação de cuidados diários prolongados. As ações devem possibilitar a ampliação da rede de pessoas com quem a família do dependente convive e compartilha cultura, troca vivências e experiências (BRASIL, 2009, p. 24-25).

No nível da Proteção Especial de Alta complexidade, temos o importante serviço de Acolhimento institucional para idosos com 60 anos ou mais, de ambos os sexos, independentes e/ou com diversos graus de dependência. Eis o que está previsto para esse serviço:

A natureza do acolhimento deverá ser provisória e, excepcionalmente, de longa permanência quando esgotadas todas as possibilidades de auto-sustento e convívio com 
os familiares. É previsto para idosos que não dispõem de condições para permanecer com a família, com vivência de situações de violência e negligência, em situação de rua e de abandono, com vínculos familiares fragilizados ou rompidos. 0 serviço de acolhimento institucional para idosos pode ser desenvolvido nas seguintes modalidades:

1.Atendimento em unidade residencial onde grupos de até 10 idosos são acolhidos. Deve contar com pessoal habilitado, treinado e supervisionado por equipe técnica capacitada para auxiliar nas atividades da vida diária;

2.Atendimento em unidade institucional com característica domiciliar que acolhe idosos com diferentes necessidades e graus de dependência. Deve assegurar a convivência com familiares, amigos e pessoas de referência de forma contínua, bem como o acesso às atividades culturais, educativas, lúdicas e de lazer na comunidade. A capacidade de atendimento das unidades deve seguir as normas da Vigilância Sanitária, devendo ser assegurado o atendimento de qualidade, personalizado, com até quatro idosos por quarto (BRASIL, 2009, p. 31-32).

Finalmente, o Serviço de Acolhimento em Repúblicas para idosos se destina a idosos que tenham capacidade de gestão coletiva da moradia e condições de desenvolver, de forma independente, as atividades da vida diária, mesmo que requeiram o uso de equipamentos de autoajuda.

A breve aproximação acerca dessa política na cidade de Salvador se deu durante o segundo semestre de 2011, período no qual realizamos um levantamento acerca dos programas e serviços presentes no interior das políticas da Seguridade Social na cidade. 0 trabalho foi feito com base em visitas técnicas nas quais eram entrevistados representantes das instituições e, em alguns casos, os próprios idosos.

Como mostramos na análise da tipificação dos serviços, não há um trabalho pensado exclusivamente para a mulher idosa no interior da Assistência Social. 0 que constatamos com as visitas é que os próprios serviços que são previstos não estão ocorrendo de modo a assegurar a proposta da política. Vejamos.

Em visita à Secretaria do Trabalho, Ação e Desenvolvimento do Município (SETAD) tomamos conhecimento da gestão da política local. Segundo os informantes, os Centros de Referência de Assistência Social (CRAS) não estão desenvolvendo todas as atividades previstas, não havendo trabalho com idosos em todos eles. Os Centros de Referência Especializada de Assistência Social (CREAS) ficam localizados nos bairros de Bonocô e Barroquinha e os educadores fazem o monitoramento dos idosos nos bairros. Em relação à Instituição de longa permanência, principal serviço da proteção especial, oficialmente existem três instituições conveniadas com a prefeitura, sendo: São 
Francisco de Assis, Santa Clara e Irmã Dulce. 0 abrigo Dom Pedro é a única instituição pública dessa natureza.

A SETAD recebe denúncias através do disque 100, que é um serviço de atendimento ao idoso. As denúncias, em sua maioria, estão relacionadas à violência no âmbito familiar devido ao uso de drogas por parte dos membros da família e relacionadas a questões financeiras.

Na Secretaria de Desenvolvimento Social e Combate à Pobreza do estado da Bahia/SEDES-BA, visitamos a Superintendência de Assistência Social, onde o técnico de referência sobre o idoso explicou que antes do SUAS, a proteção social ao idoso era organizada por um órgão específico, a Secretaria do Trabalho e Ação Social (SETRAS) que mantinha um Programa de Atendimento ao Idoso. Com a implementação do SUAS, a proteção ao idoso passa a fazer parte da estruturação desse sistema, junto com programas para outras parcelas da população considerada vulnerável, integrando a Proteção Social Básica e a Proteção Social Especial.

$\mathrm{Na}$ proteção social básica, existem 3 serviços: o Serviço de Convivência e Fortalecimento de Vínculos, o Serviço de Proteção Básica no Domicílio para Pessoas Idosas e o Benefício de Prestação Continuada. Esses serviços são desenvolvidos, em alguma medida, no CRAS. Dos 417 municípios baianos, apenas 3 não têm CRAS. Nos CRAS, o principal serviço desenvolvido é o Serviço de Fortalecimento de Vínculos que é basicamente realizado por meio dos grupos de convivência de idosos e, em alguns municípios, por um Centro de Convivência de Idosos.

Todos os municípios recebem um recurso, ainda que pequeno, para as ações de convivência e fortalecimento de vínculos, da União ou Estado. Quando o CRAS não tem uma boa estrutura para a realização dos centros, pode contratar os serviços de outra instituição para a implementação dos mesmos. Em Salvador, segundo o entrevistado, esse serviço é precário. Quanto ao Serviço de Proteção Básica no Domicílio para Pessoas Idosas, ele não está funcionando no Estado, pois não há um repasse financeiro do governo para que este serviço se concretize.

Recebemos a informação de que esse trabalho de visita domiciliar acaba sendo feito pelos agentes comunitários. No tocante ao BPC, a informação obtida é de que os CRAS fazem o trabalho de encaminhamento para o benefício, bem como o Plano de Inserção e Acompanhamento ${ }^{8}$ do beneficiário, mas esse último não está ocorrendo plenamente no estado.

\footnotetext{
${ }^{8} 0$ Plano de Inserção e Acompanhamento dos Beneficiários do BPC é o instrumento por meio do qual o Distrito Federal e os Municípios estabelecem ações voltadas para a garantia, aos beneficiários do BPC, de acesso a outros serviços da assistência social e demais políticas públicas. Para tal, uma de suas diretrizes é
} 
Na Proteção Especial, no nível da média complexidade, a informação é que não há atividades específicas. No nível da alta complexidade, o trabalho realizado é o Serviço de Acolhimento Institucional para Idosos que é feito apenas no nível das instituições de longa permanência, apesar de estarem previstos outros serviços.

Por meio dessas visitas, percebemos duas questões: a proteção se concentra em dois níveis, o mais básico e o de maior complexidade, inexistindo serviços essenciais à população idosa pobre; não há informações sistematizadas sobre os usuários e os serviços.

Depois de conhecermos as principais secretarias e órgãos gestores, nosso próximo passo foi a pesquisa nos serviços. Nesse sentido, um primeiro passo seria conhecer o nível básico de proteção, nos CRAS, onde pretendíamos abordar os candidatos ao BPC, que devem ser referenciados nesses Centros antes de serem encaminhados à Previdência, política gestora do benefício. Contudo, entramos em contato com a precariedade do trabalho nos CRAS em Salvador e com o fato de que os programas para idosos previstos para esse nível de proteção, o Serviço de Fortalecimento de Vínculos, o Serviço de Proteção Social Básica no Domicílio para idosos e o Plano de Inserção e Acompanhamento dos Beneficiários do BPC, não estavam ocorrendo de forma efetiva. Continuando as investigações, obtivemos informações de que os Centros Sociais Urbanos (CSU's) desenvolviam trabalhos com idosos, algo semelhante ao que é previsto para 0 trabalho de fortalecimento de vínculos. Partimos, então, para os CSU's e nossa pesquisa chegou a conhecer o trabalho de dois deles: Vasco da Gama que atende 90 idosas e Narandiba, com 120 inscritas.

De modo geral, os Centros têm um funcionamento comum, ou seja, desenvolvem um trabalho aos moldes de um centro de convivência onde as mulheres são presença quase exclusiva. Das atividades realizadas com as idosas, destacam-se as oficinas, nas quais elas são as agentes multiplicadoras das técnicas de artesanato (pintura, tapeçaria, vagonite, tricô, fuxico, crochê, etc.). São escolhidas duas idosas de cada CSU para participar de cursos sobre técnicas em artesanatos e ficam incumbidas de repassar esse aprendizado para as demais integrantes dos grupos de convivência. As técnicas de cada CSU se reúnem mensalmente para planejamento das atividades, ressaltando que essas atividades devem se adequar à realidade de cada comunidade. Os encontros são realizados três vezes por semana: segunda e quarta, horário integral e sexta apenas pela manhã. Um dos Centros tem parceria informal com o Posto de Saúde da Família e a Escola de Enfermagem da UFBA. Os profissionais dos postos de saúde fazem aferição de pressão arterial e promovem o Espaço Auto-estima, no qual são prestados serviços de

o acompanhamento dos beneficiários e de suas famílias, bem como o monitoramento e a reavaliação dos benefícios. 
manicure, pedicure e cabeleireiro. Os alunos do curso de Enfermagem realizavam palestras e dinâmicas voltadas para sensibilização acerca da importância da higiene pessoal. Em outro centro, a parceria é com professores de educação física. A dinâmica das atividades é comum à maioria dos grupos de convivência: as idosas são ativas, interagem bastante e se dedicam às atividades.

No que tange ao financiamento, os recursos advindos da SEDES vão para os CSU's, mas não direcionados para o trabalho com as idosas, pois há outras frentes de trabalho que são priorizadas. Então, o material para realizar as atividades é incipiente e muitas vezes fruto de doação das próprias profissionais. 0 Centro oferece café da manhã, almoço e lanche da tarde e as idosas ficam no local desde a manhã até a tarde. São cobrados $\mathrm{R} \$ 3,00$ mensais das idosas.

Nas visitas aos dois centros, entramos em contato com a coordenadora e com a técnica de referência. Apesar de registrarmos o empenho e a dedicação da equipe de profissionais envolvida no trabalho, surpreendeu-nos o caráter emergencial e a pouca estrutura para a realização das atividades, o que compromete a concretização das propostas, enquanto serviço público de qualidade e que integra as diretrizes de uma política maior, no caso a PNAS.

Alguns elementos chamaram nossa atenção nesse sentido. 0 primeiro diz respeito ao fato de que, em um dos centros, há 15 idosas afastadas das atividades, pois estão acometidas por alguma enfermidade. Para o acompanhamento dessas idosas, as profissionais realizam visitas domiciliares todas as sextas no período da tarde e, nos casos em que as idosas estão hospitalizadas, elas vão até os hospitais. Esse trabalho é fruto de enorme esforço pessoal das profissionais que, muitas vezes, vão caminhando até as residências das idosas, levam medicamentos, enfim, prestam um serviço de assistência. Contudo, o trabalho tem um caráter voluntário, pois depende da "boa vontade" das profissionais de cada CSU. Esse dado chamou nossa atenção para o fato de que a PNAS não está plenamente implementada, deixando de oferecer serviços fundamentais como o de acompanhamento domiciliar. Esse serviço, que é um direito, garantiria aos idosos e suas famílias, tantas vezes com dificuldades para exercer 0 cuidado dos mais velhos, um apoio efetivo nesse sentido.

Ainda sobre essa situação, registramos um segundo dado, mais grave: o afastamento de uma das idosas provavelmente teria sido em consequência de violência praticada pela filha e, justamente nesse caso, as profissionais interromperam 0 acompanhamento, pois entenderam que a situação estava resolvida depois de uma conversa com essa filha. Não houve nenhum tipo de acompanhamento ou encaminhamento para a verificação da situação de violência e garantia de proteção da idosa. Isso mostra a necessidade de que esse atendimento seja feito por profissionais 
atualizados sobre as políticas e direitos dos idosos, capazes de garantir acesso e efetivação de direitos.

Apenas mais um dado observado nesse mesmo sentido: uma das idosas que frequentava o Centro no dia de nossa visita tinha grande dificuldade de locomoção e precisava pagar a uma jovem para ajudá-la em seu percurso para a casa. A jovem em questão, encontrava-se no local e estava bastante impaciente com a idosa, querendo conduzí-la logo à sua casa, enquanto a idosa queria permanecer no Centro. Por fim, ela teve que partir, pois não havia outro meio de retornar. Mais uma vez, aqui, temos 0 registro de uma questão que não é contemplada no trabalho feito nos centros de convivência, qual seja, o fato de que esses espaços, até pela localização muitas vezes difícil, acabam reunindo as idosas que encarnam o "envelhecimento ativo" e deixando, sem acompanhamento, idosas que, por motivo de doença ou outro, não frequentam esses espaços. A idosa em questão ainda é frequentadora do Centro, mas apenas pelo fato de que ela paga para ser acompanhada, uma vez que não recebe atenção dos filhos e mora sozinha. Contudo, fica sujeita a arranjos e negociações informais com as jovens do bairro que se tornam acompanhantes, sem uma formação ou um vínculo afetivo com a idosa.

Nosso contato com as idosas integrantes desses dois grupos foi curto e se deu por meio de conversas individuais e de uma atividade em grupo. Nesse breve contato, alguns dados da realidade puderam ser conhecidos. Elas têm idades entre 60 e 90 anos, com predomínio da faixa entre 65 e 75 anos, são aposentadas ou pensionistas, não havendo beneficiárias do BPC. Elas recebem salário mínimo, na grande maioria dos casos; estão envolvidas em atividades domésticas e/ou na provisão do lar; têm relações com filhos e netos, marcadas por trocas e responsabilidades; muitas são viuvas, têm a necessidade de um espaço de convivência fora do âmbito doméstico, bem como vivenciam as dificuldades financeiras para fazer face às despesas consigo e com a família. Ou seja, buscando conhecer as usuárias da política de Assistência, deparamo-nos com aposentadas pobres, que ocupam esse espaço comunitário de convivência que é um dos serviços assistenciais previstos pela PNAS.

Esse perfil chama nossa atenção para a significativa presença da mulher idosa na família do trabalhador pobre no Brasil, presença que é evidenciada nos estudos contemporâneos, mas que não é algo necessariamente recente. Se observamos bem, vemos que essas mulheres foram todas cuidadoras de parentes mais velhos e mais jovens, muitas vezes simultaneamente. A complementaridade de papéis e funções é algo significativo em suas vidas e remonta não só ao seu atual estágio de vida mas à sua condição como antigas trabalhadoras. A trajetória dessas trabalhadoras, que tiveram um papel essencial como força de trabalho, faz parte das "práticas invisíveis" (LOBO et al., 1986) da nossa história. Apesar da forte vinculação ao espaço doméstico e à função da 
ajuda e cuidado, essa antiga trabalhadora contribuiu historicamente para a regulamentação do trabalho feminino, mostrando como, na organização familiar do trabalhador brasileiro, a mulher tem um papel importante na reprodução material, muito além da tradicional identidade de figura dependente do sistema previdenciário. E essa é uma questão ainda hoje pertinente à realidade da mulher trabalhadora, cujo papel social mudou bastante ao longo dessas décadas, mas cuja inserção em sistemas de proteção e direito parecem ainda obedecer a antigos acordos.

A ampliação da cobertura previdenciária no Brasil, desde a década de 1970, tem se revelado, segundo as estatísticas mais recentes, mecanismo importante de garantia de renda para as idosas. Com a diminuição da mortalidade da população idosa, mais acentuada entre as mulheres, o tempo de recebimento de benefícios se amplia e as velhas passam a figurar como beneficiárias de destaque nesse sistema (CAMARANO, 2003).

Na Região Metropolitana de Salvador, do total de 331.000 pessoas com 60 anos ou mais de idade, 38,4\% são homens, e 61,6\% são mulheres (IBGE, 2010). Não temos 0 dado da população feminina aposentada em Salvador, mas no Nordeste, do total de 3.102.000 mulheres com 60 anos ou mais, 55,3\% são aposentadas, 13,4\% pensionistas, $11,4 \%$ aposentados e pensionistas, e mulheres em outras situações correspondem a 19,9\% (IBGE, 2010).

Embora a proteção previdenciária pareça ser, de fato, fundamental para a mulher idosa, o que trazemos para a discussão é que, para as aposentadas mais pobres, como é o caso das que frequentam os CSU's, a proteção social deve contemplar proteção e apoio para a família, uma vez que as pesquisas mostram o aumento da proporção de mulheres chefes de família, provendo e cuidando de gerações mais jovens (CAMARANO, 2003). Como mostramos, a inserção social dessas idosas se dá nos bairros periféricos e, portanto, o trabalho feito em nível de proteção básica é de suma importância para elas. Contudo, esse trabalho se encontra precarizado em Salvador, como demonstramos, centrando-se apenas nos centros de convivência.

No tocante à própria Previdência Social não podemos deixar de considerar suas reformas recentes e a própria questão das iniquidades de gênero presentes na estruturação dessa política. Pensar na desigualdade de aposentadorias com relação às mulheres, é compreender que esta desigualdade vem de um momento anterior, momento em que as mulheres mais velhas se inseriram na esfera produtiva de maneira desigual, com salários menores e empregos precários, o que, vale dizer, é ainda uma realidade contemporânea. Além disso, a vida das mulheres, tanto das gerações antigas como atuais, é mais marcada por períodos de interrupção de atividades laborativas em função da necessidade de cuidar dos filhos e/ou de outros familiares dependentes. Tudo isso contribui para a redução das cotizações femininas, bem como atrasa a obtenção do 
tempo necessário para aposentar e para que a cobertura previdenciária dispensada à mulher seja menor que a dispensada ao homem.

Outro dado importante nessa discussão é aquele que aponta como eixo central as desigualdades de gênero em relação ao trabalho e à proteção social como traços que permeiam a história de várias gerações de mulheres. A reestruturação produtiva do capitalismo e o neoliberalismo estabelecem uma relação com o crescimento do emprego das mulheres. Por exemplo: o trabalho terceirizado, por permitir a realização de atividades no espaço doméstico, é frequentemente destinado às mulheres, ou seja, a mulher não se desloca do seu ambiente doméstico, sendo muito vantajoso ao capital, pois não é forçoso se pagar benefícios sociais e trabalhistas. Assim, o capital explora a mulher enquanto força de trabalho e se apropria de suas funções reprodutivas (NOGUEIRA, 2010).

As desigualdades existentes entre as aposentadorias masculinas e femininas resultam da persistência das discriminações sexuais no mercado de trabalho, assim como da precarização do emprego feminino e da desigual divisão do trabalho doméstico (SABOIA, 2006, p. 127).

Se as mulheres mais velhas enfrentaram essa situação de trabalho precário e informal durante sua vida produtiva, hoje, muitas vezes, deparam-se com essa realidade, por meio do recebimento de baixos proventos, bem como através da convivência com filhas e netas que reproduzem essa condição.

\section{CONSIDERAÇõES FINAIS}

0 breve exame da proteção social para idosos na Política de Assistência Social em Salvador revela uma tendência clara: os programas previstos nas políticas não estão se realizando, sobretudo aqueles que, na área da saúde e assistência, preconizam a atenção domiciliar e o cuidado com os idosos mais fragilizados.

A tônica, também na cidade de Salvador, é a mesma registrada nas discussões teóricas: a mobilização da família e dos laços comunitários, ação entendida como preventiva de agravos no campo da saúde e assistência. Ficam sem cobertura pública, nesse modelo, os idosos dependentes, que necessitam de cuidadores, bem como aqueles que sofrem violência e que, raramente, frequentam centros de convivência ou procuram serviços de saúde. Isso, sem contar os idosos sozinhos, mas que não se encontram em situação de abrigamento. Todos esses são grupos de idosos que parecem invisíveis para as políticas. A atenção é pensada para idosos que tenham suas famílias, seus cuidadores e que estão em boa condição de saúde para frequentarem grupos de lazer e sociabilidade. 
Contudo, o que o estudo pretendeu mostrar é que as políticas reproduzem alguns estereótipos sobre a família e os idosos, naturalizando sobretudo o papel da família protetora e do idoso como um sujeito que apenas observa os processos de mudanças, mas não é sujeito neles. Ou seja, as políticas parecem não acompanhar os novos papéis e necessidades dos idosos e de suas famílias. Por exemplo, as políticas sociais no Brasil negligenciam a questão fundamental posta pelos cuidados com os dependentes que ficam a cargo da família, sobretudo das mulheres e, tantas vezes, das mulheres velhas, enfocando apenas nos gastos do Estado e sua necessidade de cortes.

Isso fica muito claro quando falamos de mulheres velhas que vivenciaram, em suas trajetórias, importantes mudanças em seus papéis e condição, ao mesmo tempo em que continuaram sendo alvo de discriminação e desigualdade de tratamento.

As idosas que frequentam os CSU's são aposentadas/pensionistas, beneficiárias da Previdência e usuárias da Assistência. São idosas pobres. Sua situação mostra, em parte, esses novos "lugares" da velhice feminina: elas são senhoras ativas, que procuram se cuidar e manter uma vida socialmente rica, mas sem que isso signifique a vivência de uma liberdade plena, ou controle de seu tempo e escolhas, inclusive quanto a seus gastos. Isso, pois são mulheres que ainda têm responsabilidades familiares, o que faz com que, muitas vezes, sua participação em grupos de convivência seja fruto de esforço pessoal e, em alguns casos, tenha também algum impacto em sua vida material. Sobre isso, algumas idosas relataram a importância da alimentação oferecida pelos Centros na sua reprodução diária, bem como na de sua família.

A participação em centros de convivência em seus bairros é uma demanda desse grupo social. Contudo, pudemos observar que essas aposentadas apresentam outras demandas para a Política de Assistência, as quais poderiam ser atendidas se tal política fosse efetivada. É claro que o trabalho nos CSU's cumpre papel importante no "fortalecimento de vínculos", mas, em poucas visitas, percebemos como uma série de direitos das idosas são negligenciados, mesmo porque a realidade social dessas mulheres não é claramente conhecida pela instituição.

Penso, contudo, que essa não é a análise conclusiva desse quadro. Apesar, é claro, da discussão aqui proposta ter um cunho muito preliminar, carecendo de mais dados, ela aponta para algo que é muito difícil trabalhar no contexto da política social, sobretudo para as populações mais "vulneráveis", identificadas, dentre outros grupos, com os velhos e as mulheres. Nesse contexto de proteção social, existe uma lógica bastante perversa de naturalização de papéis que reforça a subalternidade dos grupos que deveriam ser emancipados e justifica uma política pobre para os mais pobres. Nesse caso, o reforço ao papel da idosa ativa, mas também da mulher que provê a família de cuidados e/ou financeiramente, contribui para o silêncio social sobre as múltiplas 
tarefas assumidas pela idosa e, até mesmo em função disso, suas ampliadas necessidades sociais que, parece-nos, estão para além dos serviços que lhes são prestados.

\section{REFERÊNCIAS}

BEHRING, Elaine Rosseti. Brasil em contra-reforma: desestruturação do estado e perda de direitos. 2. ed. São Paulo: Cortez, 2008.

BRASIL. Lei $n$. 10.741, de $1^{\circ}$ de outubro de 2003. Dispõe sobre o Estatuto do Idoso e dá outras providências. Disponível em:

<http://www.planalto.gov.br/ccivil_03/leis/2003/L10.741.htm>. Acesso em: 24 nov. 2012.

. Lei n. 8.069, de 13 de julho de 1990. Dispõe sobre o Estatuto da Criança e do Adolescente e dá outras providências. Disponível em:

<http://www.planalto.gov.br/ccivil_03/leis/L8069.htm>. Acesso em: 24 nov. 2012.

. Lei $n^{\circ}$ 8.742, de 7 de dezembro de 1993. Dispõe sobre a organização da Assistência Social e dá outras providências. Disponível em: <http://www.planalto.gov.br/ccivil_03/leis/L8742.htm>. Acesso em: 24 nov. 2012.

. Ministério do Desenvolvimento Social. Tipificação nacional de serviços socioassistenciais. Brasília: Ministério do Desenvolvimento Social, 2009. Disponível em: $<$ http://www.mds.gov.br/assistenciasocial/protecaobasica/cras/documentos/Tipificacao \%20Nacional\%20de\%20Servicos\%20Socioassistenciais.pdf>. Acesso em: 24 nov. 2012.

. Política Nacional de Assistência Social - PNAS/2004. Disponível em:

$<$ http://cursos.unipampa.edu.br/cursos/servicosocial/files/2011/05/Pol\%C3\%ADticaNacional-de-Assist\%C3\%AAncia-Social-PNAS1.pdf> . Acesso em: 24 nov. 2012.

. Sistema Único de Assistência Social (SUAS). 2005. Disponível em:

$<$ http://www.mds.gov.br/assistenciasocial/suas>. Acesso em: 24 nov. 2012.

CAMARANO, Ana Amélia. Mulher idosa: suporte familiar ou agente de mudança? Revista de Estudos Avançados, São Paulo, v. 7, n. 49, set./dez. 2003.

CAMARANO, Ana Amélia; PASINATO Maria Tereza. 0 envelhecimento populacional na agenda das políticas publicas. In: CAMARANO, Ana Amélia (Org.). Os novos idosos brasileiros: muito além dos 60? Rio de Janeiro: IPEA, 2004.

COUTO, Berenice Rojas. O direito social e a assistência social: uma equação possível? 2. ed. São Paulo:Cortez, 2006.

DEBERT, Guita Grin. A reinvenção da velhice: socialização e processos de reprivatização do envelhecimento. São Paulo: EDUSP/FAPESP, 1999. 
FONTE, Isolda Belo. Diretrizes internacionais para o envelhecimento e suas consequências no conceito de velhice. In: ENCONTRO DA ASSOCIAÇÃO BRASILEIRA DE ESTUDOS POPULACIONAIS, 12., 2002, Ouro Preto. Anais... Ouro Preto: ABEP, 2002.

GOLDANI, Ana Maria. Família, gênero e políticas: famílias brasileiras nos anos 90 e seus desafios como fator de proteção. Revista Brasileira de Estudos da População, Rio de Janeiro, v. 19, n. 1, jan./jun. 2002.

. Relações intergeracionais e reconstrução do estado de bem-estar. Por que se deve repensar essa relação para o Brasil? In: CAMARANO, Ana Amélia (Org.). Os novos idosos brasileiros: muito além dos 60? Rio de Janeiro: IPEA, 2004. p. 211-250.

IBGE. Síntese de indicadores sociais: uma análise das condições de vida. Rio de Janeiro, 2010. Disponível em:

<http://www.ibge.gov.br/home/estatistica/populacao/condicaodevida/indicadoresminim os/sinteseindicsociais2010/SIS_2010.pdf > . Acesso em: 24 nov. 2012.

KOHLI, Martin. La présence de l'histoire. In: ATTIAS-DONFUT, Claudine (Org.). Les solidarités entre générations: vieillesse, familles, état. [Paris]: Éditions Nathan, 1995.

LOBO, Elizabeth Souza et al. A prática invisível das operárias. In: KARTCHEVSKY, Andrée et al. 0 sexo do trabalho. Rio de Janeiro: Paz e Terra, 1986. p. 131-144.

MOTA, Ana Elizabete. A centralidade da Assistência Social na Seguridade Social brasileira nos anos 2000. In: MOTA, Ana Elizabete (Org.). 0 mito da assistência social: ensaios sobre Estado, política e sociedade. 2. ed. São Paulo: Cortez, 2008. p. 133-146.

MOTTA, Alda Brito. As dimensões de gênero e classe social na análise do envelhecimento. Cadernos Pagu, Campinas, v. 13, p. 191-121, 1999.

NOGUEIRA, Cláudia Mazzei. As relações sociais de gênero no trabalho e na reprodução. Aurora, Marília, ano 4, v. 6, ago. 2010.

SAB0IA, Vivian Aranha. As desigualdades de gênero na Previdência Social na França e no Brasil. Cadernos CRH, Salvador, v. 19, n. 46, jan./abr. 2006.

SIMÕES, Júlio Assis. "A maior categoria do país": o aposentado como ator político. In: BARROS, Myriam Moraes Lins (Org.). Velhice ou terceira idade? estudos antropológicos sobre identidade, memória e política. Rio de Janeiro: Fundação Getúlio Vargas, 1998.

TEIXEIRA, Solange Maria. Envelhecimento e trabalho no tempo do capital: implicações para a proteção social no Brasil. São Paulo: Cortez, 2008.

VICCARI, Eunice Maria. Assistência Social como direito universal: entre a concepção teórica e a provisão. 2008. 172 f. Tese (Doutorado em Serviço Social) - Pontifícia Universidade Católica, Rio Grande do Sul, 2008. 